\title{
A Case-Control Study on Oxidative Stress and Antioxidant in Haemorrhagic and Ischemic Stroke Patients
}

Dr. Moin Sabeer ${ }^{1}$, Dr. Khaja Moinuddin ${ }^{2 *}$

${ }^{1}$ Associate Professor, Department of Biochemistry, MNR Medical College and Hospital, Fasalwadi, Telangana 502285, India

${ }^{2}$ Assistant Professor, Department of Biochemistry, ESIC Dental College, SH10, Gulbarga University, Jnana Ganga, Kalnoor, Gulbarga, Karnataka 585106, India

\author{
DOI: $\underline{10.36348 / \mathrm{sijb} .2020 . \mathrm{v} 03 \mathrm{i} 11.002}$ \\ | Received: 12.11.2020 | Accepted: 23.11.2020 | Published: 26.11.2020
}

*Corresponding author: Dr. Khaja Moinuddin

\section{Abstract}

Introduction: Stroke patients with haemorrhagic and ischemic strokes were compared with regard to stroke severity, mortality, and cardiovascular risk factors. Material and Methods: This prospective and descriptive study was done during January 2019 and September 2020. This case-control study was conducted on an overall population of 120 individuals (40 haemorrhagic, 40 ischemic strokes and as the case groups; 40 healthy individuals as the control group). The diagnosis was made by the clinical examination and brain CT scan. Our excluding criteria were a previous history of a cerebrovascular event, history of a recent infectious or inflammatory disease, cancer, autoimmune disorder, haematological disorder, renal or hepatic disease, or use of immune-suppressive or anti-inflammatory drugs in the previous two months. Result: A total of 120 individuals (40 haemorrhagic strokes and 40 ischemic strokes as the case groups; 40 individuals as the control group) were identified during the study follow-up. The increase in MDA in ischemic stroke (ISPs) and Haemorrhagic stroke patients is highly significant $(\mathrm{P}<0.001)$ when compared to control subjects. This indicates that lipid peroxidation is significantly increased in ISPs and the increase in MDA is more in ISPs than haemorrhagic stroke patients $(\mathrm{p}<0.001)$. Similarly, nitric oxide levels are also increased in both ISPs and HSPs. GPX levels are decreased significantly in ISPs and HSPs compared to control subjects(p<0.001). Maximum decline in GPX is found in ISPs with HSPs $(\mathrm{p}<0.001)$. The Uric acid levels are significantly increased in ISPs and HSPs when compared to control subjects $(\mathrm{p}<0.003)$ and the increase is more in ISPs with HSPs (Table 3). The SOD levels are decreased significantly $(\mathrm{p}<0.05)$ in ISPs and HSPs when compared to control subjects, whereas its levels are slightly decreased in ISPs with HSPs. Similarly, Catalase levels also decreased in both ISPs and HSPs. Conclusion: Hence, showed a direct positive correlation with infarct size (Ischemic stroke) but less in hemorrhagic stroke when compared with the control group. The antioxidative parameters like Catalase and superoxide dismutase were decreased both ischemic and hemorrhagic stroke when compared with control.

Keywords: Oxidative stress, antioxidant, haemorrhagic and ischemic stroke.

Copyright () 2020 The Author(s): This is an open-access article distributed under the terms of the Creative Commons Attribution 4.0 International License (CC BY-NC 4.0) which permits unrestricted use, distribution, and reproduction in any medium for non-commercial use provided the original author and source are credited.

\section{INTRODUCTION}

Stroke is defined by the World Health Organization as a clinical syndrome consisting of rapidly developing clinical signs of focal (or global in case of coma) disturbance of cerebral function lasting more than 24 hours or leading to death with no apparent cause other than a vascular origin [1]. Stroke is classified broadly into three categories; ischemic stroke, haemorrhagic stroke and subarachnoid haemorrhage. Ischemic stroke occurs due to blockage of a blood vessel which limits the blood supply to the brain whereas haemorrhagic stroke occurs due to rupture of a blood vessel leading spillage of blood in the intracranial cavity [2]. Depending on the site of blood spillage the haemorrhagic stroke could be classified as intracerebral haemorrhage or subarachnoid haemorrhage. Approximately $60-80 \%$ of all strokes are ischemic [3].

Stroke is the second most common cause of mortality and the third most common cause of disability worldwide. Globally, $68 \%$ of all strokes are ischemic and $32 \%$ are haemorrhagic [4]. Numbers from the USA differ a little with $87 \%$ of all strokes being ischemic, $10 \%$ haemorrhagic and about $3 \%$ being subarachnoid haemorrhage [5]. Data regarding the prevalence of stroke in India is lacking however, it can have extrapolated from the data available from the West. In a study done by Banerjee et al., in 2001 crude prevalence rate of stroke in India was 147/100,000 and the annual 
incidence rate was 36/100,000. Women had substantially higher age-adjusted prevalence rate (564/100,000 for women vs 196/100,000 for men) and incidence rate $(204 / 100,000$ for women vs $36 / 100,000$ for men) [6]. The overall prevalence of stroke ranges from 147-922/100,000 in various studies [7].

Oxidative stress is the development and progression of various human diseases. Several types of reactive species are generated in the body as a result of metabolic reactions in the form of free radicals or nonradicals. These species may be either oxygen-derived or nitrogen derived and called prooxidants. They attack macromolecules including protein, DNA and lipid etc. causing cellular/tissue damage [8]. To counter their effect, the body is endowed with another category of compounds called antioxidants. These antioxidants are produced either endogenously or received from exogenous sources and include enzymes like superoxide dismutase, catalase, glutathione peroxidase and glutathione reductase, minerals like $\mathrm{Se}, \mathrm{Mn}, \mathrm{Cu}$ and $\mathrm{Zn}$, and vitamins like vitamin $\mathrm{A}, \mathrm{C}$ and $\mathrm{E}$. Other compounds with antioxidant activity include glutathione, flavonoids, bilirubin and uric acid etc [9].

In a healthy body, prooxidants and antioxidants maintain a ratio and a shift in this ratio towards prooxidants give rise to oxidative stress. This oxidative stress may be either mild or severe depending on the extent of shift and remains the cause of several diseases such as cardiovascular diseases, neurological diseases, malignancies, renal diseases, diabetes, inflammatory problems, skin diseases, ageing, respiratory diseases, liver diseases and different types of viral infections [10]. As more and more reports are pouring in; a lot of information is being unfolded about oxidative stress in relation to several other diseases.

Taking account of the above-mentioned data and because stroke shares common risk factors with a road accident, we can safely assume that India has a very high incidence of stroke as well.

\section{MATERIAL AND METHODS}

This prospective and descriptive study was done during January 2019 and September 2020. This case-control study was conducted on an overall population of 120 individuals (40 haemorrhagic, 40 ischemic strokes and as the case groups; 40 healthy individuals as the control group). The diagnosis was made by the clinical examination and brain CT scan.

Our excluding criteria were a previous history of a cerebrovascular event, history of a recent infectious or inflammatory disease, cancer, autoimmune disorder, haematological disorder, renal or hepatic disease, or use of immune-suppressive or anti-inflammatory drugs in the previous two months. Patients who were lost during follow-up for any cause other than death were also omitted from the study

Venous blood samples were obtained on admission. Blood samples were centrifuged at room temperature at $3000 \mathrm{rpm}$ for $10 \mathrm{~min}$; and after sera were separated, they were analysis.

\section{STATISTICAL ANALYSIS}

The collected data were compiled in MS Excel sheet for analysis. Analysed in Statistical Package for the Social Sciences (SPSS) version $25^{\text {th }}$ were applied. Quantitative data were represented in the form of mean and standard deviation. To check the significance difference between case and control group comparison unpaired ' $t$ ' test was applied quantitative data was represented in the form of pie diagram and bar diagram. p-value $<0.05$ indicates statistical significant.

\section{RESULTS}

A total of 120 individuals (40 haemorrhagic strokes and 40 ischemic strokes as the case groups; 40 individuals as the control group) were identified during the study follow-up. Their age varied between 40 and $8081(53.74 \pm 7.53$ and $52.73 \pm 7.32$ in IS and HS, respectively) and there was no significant difference of age between two groups. Whereas, BMI $24.1 \pm 2.9$ in a control group, $23.2 \pm 2.7$ in HS group and $24.3 \pm 2.5$ in IS group.

Table-1: Characteristics of the Whole Group of Patients

\begin{tabular}{|l|l|l|l|}
\hline Characteristics & Control group & Haemorrhagic stroke & Ischemic stroke \\
\hline n & 40 & 40 & 40 \\
\hline Age, y, Mean \pm SD & $51.43 \pm 7.32$ & $53.74 \pm 7.53$ & $52.73 \pm 7.32$ \\
\hline Males & $20(50 \%)$ & $23(55.2)$ & $21(58)$ \\
\hline Female & $20(50 \%)$ & $17(44.7)$ & $19(41.9)$ \\
\hline BMI $\left(\mathrm{kg} / \mathrm{m}^{2}\right)$ & $24.1 \pm 2.9$ & $23.2 \pm 2.7$ & $24.3 \pm 2.5$ \\
\hline
\end{tabular}

Table-2: Distribution of the oxidants in Patients

\begin{tabular}{|l|l|l|l|}
\hline Characteristics & $\begin{array}{l}\text { Control group } \\
\text { Mean } \pm \text { SD }\end{array}$ & $\begin{array}{l}\text { Haemorrhagic stroke } \\
\text { Mean } \pm \text { SD }\end{array}$ & $\begin{array}{l}\text { Ischemic stroke } \\
\text { Mean } \pm \text { SD }\end{array}$ \\
\hline Malondialdehyde $(\mathrm{MDA})(\mathrm{nM} / \mathrm{mL})$ & $1.61 \pm 0.21$ & $2.43 \pm 0.62$ & $2.73 \pm 0.39$ \\
& & $\mathrm{P}<0.001$ & $\mathrm{P}<0.001$ \\
\hline Nitric oxide $(\mathrm{NO}) \mu \mathrm{g} / \mathrm{ml}$ & $3.73 \pm 0.32$ & $\begin{array}{l}4.93 \pm 0.42 \\
\mathrm{P}<0.001\end{array}$ & $\begin{array}{l}4.53 \pm 0.37 \\
\mathrm{P}<0.001\end{array}$ \\
\hline
\end{tabular}


In Table-2, the increase in MDA in ischemic stroke (ISPs) and Haemorrhagic stroke patients is highly significant $(\mathrm{P}<0.001)$ when compared to control subjects. This indicates that lipid peroxidation is significantly increased in ISPs and the increase in MDA is more in ISPs than haemorrhagic stroke patients $(\mathrm{p}<0.001)$. Similarly, nitric oxide levels are also increased in both ISPs and HSPs.

Table-3: Distribution of the Anti-oxidants in Patients

\begin{tabular}{|l|l|l|l|}
\hline Characteristics & Control group Mean \pm SD & $\begin{array}{l}\text { Haemorrhagic stroke } \\
\text { Mean } \pm \text { SD }\end{array}$ & $\begin{array}{l}\text { Ischemic stroke } \\
\text { Mean } \pm \text { SD }\end{array}$ \\
\hline Glutathione peroxides $(\mathrm{GPX})(\mu \mathrm{mol} / \mathrm{mg})$ & $9.81 \pm 2.23$ & $\begin{array}{l}4.31 \pm 0.93 \\
\mathrm{P}<0.001\end{array}$ & $\begin{array}{l}4.11 \pm 0.72 \\
\mathrm{P}<0.001\end{array}$ \\
\hline Uric acid $(\mathrm{mg} / \mathrm{dl})$ & & $6.31 \pm 0.6$ & $7.21 \pm 0.8$ \\
& $4.46 \pm 0.5$ & $\mathrm{P}<0.001$ & $\mathrm{P}<0.001$ \\
\hline Superoxide dismutase $(\mathrm{SOD})(\mathrm{U} / \mathrm{mg})$ & $14.11 \pm 0.4$ & $8.71 \pm 0.3$ & $9.23 \pm 0.7$ \\
& & $\mathrm{P}<0.001$ & $\mathrm{P}<0.001$ \\
\hline Catalase $(\mathrm{IU} / \mathrm{mg})$ & $13.21 \pm 0.5$ & $9.32 \pm 0.2$ & $8.41 \pm 0.6$ \\
& & $\mathrm{P}<0.001$ & $\mathrm{P}<0.001$ \\
\hline
\end{tabular}

GPX levels are decreased significantly in ISPs and HSPs compared to control subjects $(\mathrm{p}<0.001)$. Maximum decline in GPX is found in ISPs with HSPs $(\mathrm{p}<0.001)$. The Uric acid levels are significantly increased in ISPs and HSPs when compared to control subjects $(p<0.003)$ and the increase is more in ISPs with
HSPs (Table-3). The SOD levels are decreased significantly $(\mathrm{p}<0.05)$ in ISPs and HSPs when compared to control subjects, whereas its levels are slightly decreased in ISPs with HSPs. Similarly, Catalase levels also decreased in both ISPs and HSPs.

Table-4: Distribution of the Vitamin $\mathrm{C}$ and $\mathrm{E}$ in a control group, Ischemic stroke group and Haemorrhagic stroke

\begin{tabular}{|l|l|l|l|}
\hline Characteristics & Control group Mean \pm SD & $\begin{array}{l}\text { Haemorrhagic stroke } \\
\text { Mean } \pm \text { SD }\end{array}$ & $\begin{array}{l}\text { Ischemic stroke } \\
\text { Mean } \pm \text { SD }\end{array}$ \\
\hline Vitamin C (mg/L) & $1.32 \pm 0.36$ & $0.83 \pm 0.63$ & $0.59 \pm 0.74$ \\
\hline Vitamin E (mg/L) & $11.51 \pm 0.41$ & $8.76 \pm 0.72$ & $7.32 \pm 0.83$ \\
\hline
\end{tabular}

In Table-4, it was observed that the serum levels of Vitamin C and Vitamin E were significantly lowered in both ISPs and HSPs than those of control.

\section{DISCUSSION}

In the present study, we have focused on the relationship between serum oxidative stress and antioxidant profile and various prognostic factors of ischemic and haemorrhagic stroke. Throughout the past decades, there has been accumulating evidence of the association between oxidative stress and stroke injury, and several studies have proved oxidative damage as a mechanism underlying neuronal damage in different stages after stroke [11]. Free radicals generated in the affected area of the brain can exert their effect by lipid peroxidation leading to membrane changes and apoptosis, protein oxidation and impaired enzymatic functions and DNA oxidation that can eventually lead to cell death. While these factors are present in the brain in normal state and they have many important roles in signalling and as a defence mechanism against infections, they usually cannot cross the blood-brain barrier and their half-life is not long enough to reach significant concentrations in serum. However, following a vascular attack with or without reperfusion their modifications in plasma can reflect brain damage [12].

Various oxidative stress markers have been previously shown to be higher in ischemic stroke patients compared to control. However, until now none of these results could suggest a different diagnostic or therapeutic approach for clinicians in practice [13]. In an attempt to find a path between the biochemistry of stroke and its clinical management, we measured the plasma concentrations of various ' markers in a group of stroke patients. Malonyldealdehyde, a breakdown product of lipid peroxidation and total antioxidant capacity were chosen as indicators of the oxidant and antioxidant balance state.

This study included patients with a recent cerebrovascular accident. We assigned different prognostic factors for the two groups based on what had been previously associated with higher mortality and morbidity rate in each type. The majority of ischemic strokes are due to a thrombosis or an embolus. Previous studies have shown MDA levels are higher in ischemic patients in comparison to the general population. However, few studies have focused on the correlation between stroke severity, its outcome and MDA or other markers of oxidative state. Ozkul et al., previously reported an association between MDA and Canadian Neurological Scale Scores (CNS) [14]. In another study, Leinonen et al., observed an inverse correlation of plasma total peroxyl radical-trapping potential (TRAP) and lesion volume and a significant or inverse correlation with the scores in NIHSS and HMS and a direct correlation with BI score at all-time points after the stroke in ischemic stroke [15]. However, these 
levels were measured only at the initial presentation, and follow-up measurements could help to clarify MDA and NO changes and ischemic stroke outcomes.

Stroke is a disease of different pathophysiology and hence different subtypes. It seems that haemorrhagic patients have been under represented in the literature. One reason could be its lower incidence compared to ischemic stroke. Only 15 percent of all strokes happen because of an intracranial haemorrhage $(\mathrm{ICH})$. However haemorrhagic strokes are generally associated with greater severity and higher mortality after age, gender and relevant risk factors adjustments, and they are a major healthcare burden. Patients with haemorrhagic stroke are shown to have higher levels of oxidative biomarkers than the control population. [16] In another study among our 24haemorrhagic patients 11 had a lesion in putamen which is the most common location, 7 in the thalamus, 1 had a pontine lesion and 3 had lobar haemorrhage (1 in frontal, 2 in parietal lobe). No association between MDA levels of $\mathrm{NO}$ and the location of $\mathrm{ICH}$ was observed [17].

Our results indicate that GPX levels are decreased significantly in ISPs and HSPs but the maximum decline is observed in ISPs. GPX depletion enhances cerebral ischemic injury. Shivakumar et al., and Akila et al., have shown that GPX levels have decreased in brain regions during reperfusion for $1 \mathrm{~h}$ after moderate or severe ischemia for 0-5 hours [18]. The GPX was shown to reduce lethality, increase brain water levels and decrease MDA levels in cerebral ischemic rats when given immediately after ischemia suggesting that its anti-ischemic effects are due, in part to inhibition of lipid peroxidative responses [19]. In our study, we have found decreased GPX levels in ISPs and HSPs which indicates that the antioxidant capacity is decreased in these patients. Therefore, treatment with anti-oxidant might be beneficial to reduce MDA in ischemic stroke patients.

Our study also indicates that uric acid levels are significantly increased in ISPs and HSPs and the increase is more in ISPs compared with control. Milanlioglu et al., found similar results to that of the present study; significant differences in serum Uric acid was found between stroke patients and healthy controls [20]. Uric acid, which is the end product of purine metabolism has been regarded as a potent endogenous water-soluble antioxidant and radical scavenger in humans [21]. Uric acid plays an important role in acute ischemic stroke, as a consequence of its antioxidant properties. It is particularly effective in quenching hydroxyl superoxide and peroxynitrite radicals and may serve a protective physiological role by preventing lipid peroxidation [22]. Though uric acid is an antioxidant our study results indicate increase of uric acid levels when all other antioxidant parameter levels are decreased. This paradoxical antioxidant-prooxidant switch happens once local antioxidants like superoxide dismutase, glutathione peroxidase and catalase levels are depleted this is known as urate redox shuttle [23, 24]. Furthermore, ischemia itself causes increased generation of xanthine oxidase explaining the increased levels of uric acid in ischemic stroke patients [24, 25].

We have also found in our study that SOD levels are decreased in ISPs and HSPs when compared to control subjects, where as its levels are decreased in ISPs with HSPs. Similar to the current study, El Kossi et al., found a significant difference between the IS group and the control group, concerning serum SOD activity [26]. Moreover, Cherubini et al., and Demikaya et al., found that SOD activity decreases significantly in IS patients [27]. SOD is an endogenous antioxidant that catalyses the dismutation of the superoxide anion radical. SOD plays an important role in the defence against free radical damage in reperfusion injury help in reducing the infarct size during ischemia and reperfusion. A decrease in the levels of SOD in ischemic stroke patients and HSPs may be due to an adaptive mechanism to increased oxidative stress. A decrease in the SOD levels as observed in ISPs with HSPs indicates that antioxidant defence is impaired in these patients [28].

In our study that Catalase levels are decreased in ISPs and HSPs when compared to control subjects, where as its levels are decreased in ISPs with HSPs. Similar to the current study Cherobini et al., reported that the levels of CAT, activity in plasma and red blood cells in patients at the onset of stroke were lower than the control group [29].

Vitamin C represents the major water-soluble antioxidant in the human body. Many studies show that reduced Vitamin $\mathrm{C}$ levels are associated with increased risk of both ischemic and Haemorrhagic strokes. In this regard, Sheikh et al., reported similar findings [30]. In our present study, the serum Vitamin C levels were decreased significantly in ischemic stroke and haemorrhagic stroke patients (decreases significantly in large vessels infarcts than in small vessel infarcts) compared to controls. It may be due to the exhaustion of this antioxidant in the neutralization of free radicals which are formed in excess during ischemia and reperfusion.

Vitamin E, a potent chain-breaking lipidsoluble antioxidant, reacts with lipid peroxyl radicals eventually terminating the peroxidation chain reaction and thereby reducing oxidative damage. Some studies have shown reduced serum vitamin $E$ levels in stroke patients and this may be due to high lesion volume resulting in production of more number of free radicals from a large ischemic injury [31] It is also shown that reduced vitamin $\mathrm{E}$ levels resulted in poor clinical outcome in stroke patients. In the present study serum 
vitamin E levels were significantly decreased in ischemic stroke cases when compared to controls.

\section{CONCLUSION}

Although there is strong evidence supporting the role of oxidative stress in brain injury following a cerebrovascular attack, further research is needed to show, how it is involved in the evolution of clinical manifestations of stroke patients and its application in predicting patients' outcome.

\section{REFERENCE}

1. Broderick, J., Brott, T., Kothari, R., Miller, R., Khoury, J., Pancioli, A., ... \& Shukla, R. (1998). The Greater Cincinnati/Northern Kentucky Stroke Study: preliminary first-ever and total incidence rates of stroke among blacks. Stroke, 29(2), 415421.

2. Williams, G. R., Jiang, J. G., Matchar, D. B., \& Samsa, G. P. (1999). Incidence and occurrence of total (first-ever and recurrent) stroke. Stroke, 30(12), 2523-2528.

3. Kolominsky-Rabas, P. L., Sarti, C., Heuschmann, P. U., Graf, C., Siemonsen, S., Neundoerfer, B., ... \& von Stockert, T. R. (1998). A prospective community-based study of stroke in Germanythe Erlangen Stroke Project (ESPRO) incidence and case fatality at 1,3, and 12 months. Stroke, 29(12), 2501-2506.

4. Smith, R. W., Scott, P. A., Grant, R. J., Chudnofsky, C. R., \& Frederiksen, S. M. (1999). Emergency physician treatment of acute stroke with recombinant tissue plasminogen activator: a retrospective analysis. Academic emergency medicine, 6(6), 618-625.

5. Lewandowski, C. A., Frankel, M., Tomsick, T. A., Broderick, J., Frey, J., Clark, W., ... \& Brott, T. (1999). Combined intravenous and intra-arterial $r-$ TPA versus intra-arterial therapy of acute ischemic stroke: Emergency Management of Stroke (EMS) Bridging Trial. Stroke, 30(12), 2598-2605.

6. Banerjee, T. K., Mukherjee, C. S., \& Sarkhel, A. (2001). Stroke in the urban population of Calcutta-an epidemiological study. Neuroepidemiology, 20(3), 201-207.

7. Pandian, J. D., \& Sudhan, P. (2013). Stroke epidemiology and stroke care services in India. Journal of stroke, 15(3), 128-134.

8. Cross, C. E., Halliwell, B., Borish, E. T., Pryor, W. A., Ames, B. N., Saul, R. L., ... \& Harman, D. (1987). Oxygen radicals and human disease. Annals of internal medicine, 107(4), 526545.

9. Ignarro, L. J., Buga, G. M., Wood, K. S., Byrns, R. E., \& Chaudhuri, G. (1987). Endotheliumderived relaxing factor produced and released from artery and vein is nitric oxide. Proceedings of the National Academy of Sciences, 84(24), 9265-9269.
10. Beckman, J. S., Beckman, T. W., Chen, J., Marshall, P. A., \& Freeman, B. A. (1990). Apparent hydroxyl radical production by peroxynitrite: implications for endothelial injury from nitric oxide and superoxide. Proceedings of the National Academy of Sciences, 87(4), 16201624.

11. Mcbride, A. G., \& Brown, G. C. (1997). Production of peroxynitrite from nitric oxide, hydrogen peroxide and superoxide dismutase: pathological implications. Biochem Soc Trans. 25:409S

12. Circu, M. L., \& Aw, T. Y. (2010). Reactive oxygen species, cellular redox systems, and apoptosis. Free Radical Biology and Medicine, 48(6), 749-762.

13. Chen, H. W., Chien, M. L., Chaung, Y. H., Lii, C. K., \& Wang, T. S. (2004). Extracts from cigarette smoke induce DNA damage and cell adhesion molecule expression through different pathways. Chemico-biological interactions, 150(3), 233-241.

14. Pryor, W. A., Stone, K., Zang, L. Y., \& Bermúdez, E. (1998). Fractionation of aqueous cigarette tar extracts: fractions that contain the tar radical cause DNA damage. Chemical research in toxicology, 11(5), 441-448.

15. Stone, K., Bermudez, E., Zang, L. Y., Carter, K. M., Queenan, K. E., \& Pryor, W. A. (1995). The ESR properties, DNA nicking, and DNA association of aged solutions of catechol versus aqueous extracts of tar from cigarette smoke. Archives of biochemistry and biophysics, 319(1), 196-203.

16. DeMarini, D. M. (2004). Genotoxicity of tobacco smoke and tobacco smoke condensate: a review. Mutation Research/Reviews in Mutation Research, 567(2-3), 447-474.

17. Kong, Q., \& Lin, C. L. G. (2010). Oxidative damage to RNA: mechanisms, consequences, and diseases. Cellular and Molecular Life Sciences, 67(11), 1817-1829.

18. Siems, W. G., Grune, T., \& Esterbauer, H. (1995). 4-Hydroxynonenal formation during ischemia and reperfusion of rat small intestine. Life sciences, 57(8), 785-789.

19. Stadtman, E. R. (2004). Role of oxidant species in aging. Current medicinal chemistry, 11(9), 11051112.

20. Wang, M., Dhingra, K., Hittelman, W. N., Liehr, J. G., De Andrade, M., \& Li, D. (1996). Lipid peroxidation-induced putative malondialdehydeDNA adducts in human breast tissues. Cancer Epidemiology and Prevention Biomarkers, 5(9), 705-710.

21. Lyras, L., Cairns, N. J., Jenner, A., Jenner, P., \& Halliwell, B. (1997). An assessment of oxidative damage to proteins, lipids, and DNA in brain from patients with Alzheimer's disease. Journal of neurochemistry, 68(5), 2061-2069. 
22. Sayre, L. M., Smith, M. A., \& Perry, G. (2001). Chemistry and biochemistry of oxidative stress in neurodegenerative disease. Current medicinal chemistry, 8(7), 721-738.

23. Hayden, M. R., \& Tyagi, S. C. (2004). Uric acid: A new look at an old risk marker for cardiovascular disease, metabolic syndrome, and type 2 diabetes mellitus: The urate redox shuttle. Nutrition \& metabolism, 1(1), 10.

24. Moinuddin, K., \& Awanti, S. M. (2016). Evaluation of the relationship between glycemic parameters and serum uric acid level in type 2 diabetes mellitus patients. Age, 50, 50. International Journal of Clinical Biochemistry and Research, 3(4):395-401.

25. Leyva, F., Anker, S., Swan, J. W., Godsland, I. F., Wingrove, C. S., Chua, T. P., ... \& Coats, A. J. S. (1997). Serum uric acid as an index of impaired oxidative metabolism in chronic heart failure. European heart journal, 18(5), 858-865.

26. Toshniwal, P. K., \& Zarling, E. J. (1992). Evidence for increased lipid peroxidation in multiple sclerosis. Neurochemical research, 17(2), 205-207.
27. Dhalla, N. S., Temsah, R. M., \& Netticadan, T. (2000). Role of oxidative stress in cardiovascular diseases. Journal of hypertension, 18(6), 655-673.

28. Kašparová, S., Brezová, V., Valko, M., Horecký, J., Mlynárik, V., Liptaj, T., ... \& Dobrota, D. (2005). Study of the oxidative stress in a rat model of chronic brain hypoperfusion. Neurochemistry international, 46(8), 601-611.

29. Kerr, S., Brosnan, M. J., McIntyre, M., Reid, J. L., Dominiczak, A. F., \& Hamilton, C. A. (1999). Superoxide anion production is increased in a model of genetic hypertension: role of the endothelium. Hypertension, 33(6), 1353-1358.

30. Kukreja, R. C., \& Hess, M. L. (1992). The oxygen free radical system: from equations through membrane-protein interactions to cardiovascular injury and protection. Cardiovascular Research, 26(7), 641-655.

31. Powers, W. J., Rabinstein, A. A., Ackerson, T., Adeoye, O. M., Bambakidis, N. C., Becker, K., ... \& Jauch, E. C. (2018). 2018 guidelines for the early management of patients with acute ischemic stroke: a guideline for healthcare professionals from the American Heart Association/American Stroke Association. stroke, 49(3), e46-e99. 